\title{
Luces y sombras del Poema de Parménides en la historia de la filosofía
}

\author{
Manuel Mazón \\ Universidad de Comillas
}

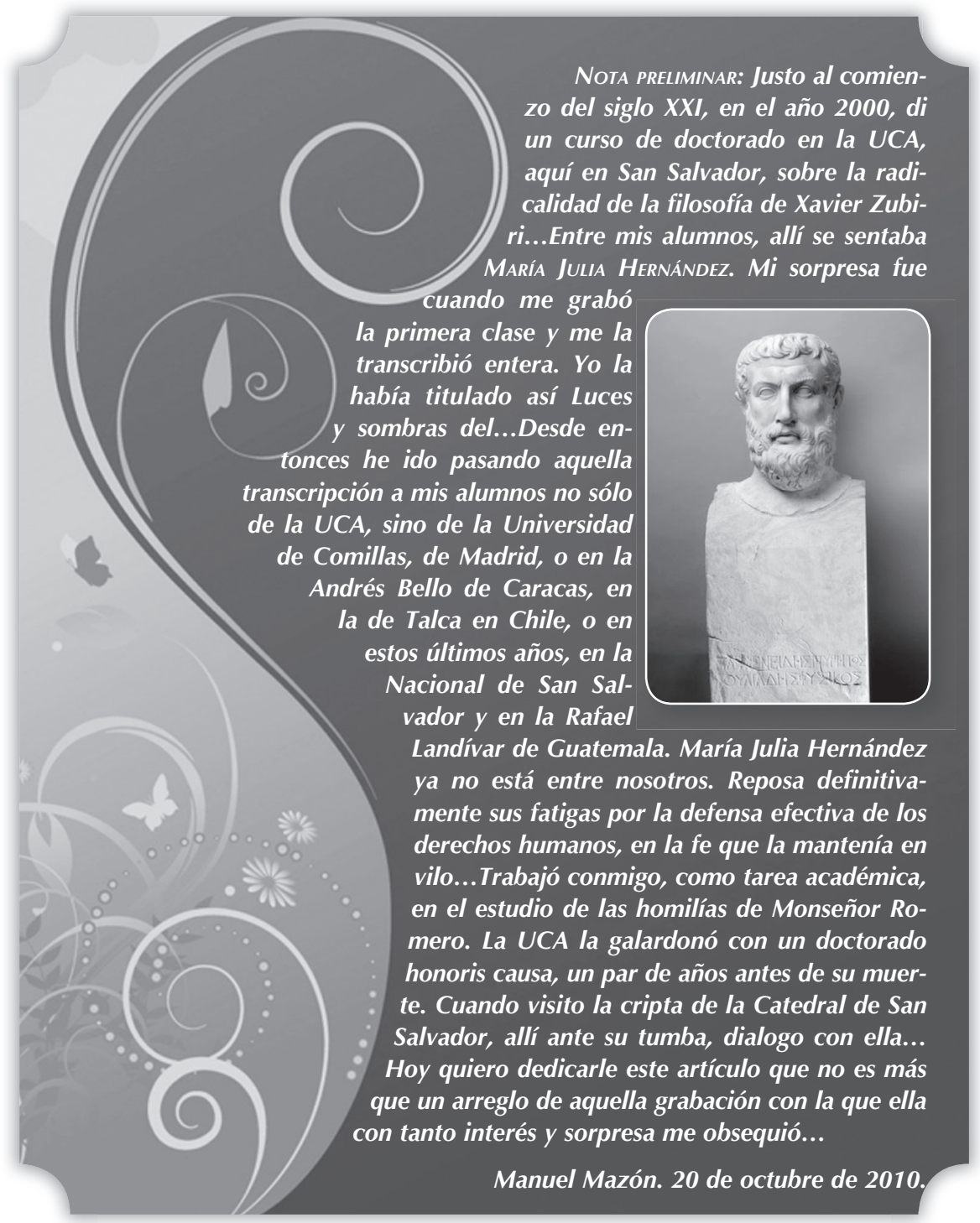


Es importante un marco de referencia de lo que podríamos Ilamar la orientación radical de la actividad filosófica. Sólo se aprende filosofía filosofando, poniéndose a filosofar... De ahí la conveniencia de un ámbito de orientación que nos ayude a "ubicar" las distintas vicisitudes que el pensamiento ha ido sufriendo en su marcha hacia la identidad con el ser a lo largo de la Historia de la Filosofía, en sus momentos más estelares.

Si nos situamos filosóficamente en el siglo XIX: en el siglo XIX se da la gran eclosión del pensamiento totalizante y de su propia historia. Su culminación podríamos decir que es la obra de Hegel. Es el Idealismo.

¿Qué significa este idealismo, en dos palabras? Habríamos de tener aquí un mural al fondo con la frase tópica, - de la que arranca la filosofía-, aquel famoso aforismo de Parménides: "que el pensamiento es igual al ser", interpretando que 'igual' es la tendencia del pensamiento: tiende al ser: - to gar noein esti to einai-, dice Parménides. Porque el pensamiento, vamos a decir, que remata en el ser. La terminal de la actividad del pensamiento siempre será el ser...

A partir de ahí, empieza la filosofía. Nos hemos retrotraído nada menos que al siglo $\mathrm{VI}$ antes de Cristo, en la antigua Grecia.

El hombre entonces lo que se plantea es saber del ser. Lo primero que se pregunta es: ¿qué es el ser?
Parménides describió el ser a la manera de una esfera, que es algo "limitado", pero que no se le pueden abarcar los límites, el principio y el final se identifican, es compacta, es maciza; por lo tanto, todo cuanto, es. Y si considero la esfera como tal, si no hubiera más que una esfera, sería inconcebible el mundo del no ser, porque toda la realidad estaría - diríamos- completada, determinada por la esfera como ser. Así concibió Parménides lo que era el ser.

Entonces, iy todo lo otro que no es ser, qué dedicación se le da por el pensamiento? El pensamiento, ¿cómo se dedica a las otras cosas que no son ser? Pues, se dedica —dice-, por la vía de la doxa. La vía de la doxa es la vía que hoy entendemos como la más clara, es el ámbito de la opinión. La palabra doxa en griego significa opinión. En el sentido más simple y vulgar: yo opino esto, tú opinas y lo de más allá, y lo siguiente... Todas las opiniones juntas nunca llegarán a la verdad, según Parménides, pero ahí está. Se conviene en...es la vía de la convención. Algo muy ajustado, nada que tenga que ver con lo arbitrario.

¿Y cuál es la vía del ser? Es la vía de la alétheia. La palabra aletheia significa descubrimiento. Recuerda en castellano a la palabra letal. Esta palabra letal, presencia de la muerte. Lethos, en griego significa lo oculto. Muerto es lo que ocul- 
ta la vida, lo que está oculto, -letargo-, está ocultando la vida. Está en letargo, los animales que están en letargo ocultan la vida. Cuando los griegos le ponen un alfa, una $a$, a las palabras esas por delante, alethos, entonces la palabra significa exactamente lo contrario. Por lo tanto, si lethos es oculto, alethos es descubierto. Entonces, a-létheia es la verdad como descubrimiento. El pensamiento, en su ruta hacia el ser, lo que va es descubriendo ser. Luego el ser de alguna manera, está ligado al pensamiento y el pensamiento está ligado al ser. Los griegos siempre tienen una misma tendencia, que es ir, desplazarse del pensamiento al ser, porque el ser les espera, por decirlo así. ¿YY dónde les espera el ser?

Van buscando allí donde puede estar el ser encerrado, oculto. Entonces, Platón entiende que el ser está encerrado en aquello que es más propio del pensamiento. Y por eso crea un sistema que hasta hoy nos está condicionando y nos seguirá condicionando, a saber por cuánto tiempo.

Resulta que Platón como si dijera, ¿cuál es lo más cercano al pensamiento? Pues lo más cercano al pensamiento son las ideas. En el mundo de las ideas está el saber de la realidad. Entonces, ¿cuándo descansa el pensamiento según Platón? Cuando descubre el orden de las ideas. Así el orden de las ideas, diríamos, que es lo más real. Por lo tanto, para Platón, el mundo de las ideas es el mundo real.

¿A qué se contrapone este mundo real en la mentalidad de Platón? A todo aquello que está más alejado de las ideas. ¿Cuál es lo más lejano de las ideas visto desde el pensamiento? Pues todo aquello que nosotros sentimos independiente del pensamiento. Situemos ahí todas las afecciones, emociones, las sensaciones, todo tipo de realidad que de alguna manera no está controlada por el pensamiento en el sentido que no pertenece al mundo de las ideas. Así Platón dice que la realidad para el pensamiento consiste en el orden de las ideas. Y desde ese orden de las ideas se intenta también el orden de las cosas que no poseen idea, i. d., el orden del mundo sensible.

Aristóteles, aparte de un gran pensador, fue discípulo de Platón. En un momento dado, Aristóteles tuvo una duda profunda respecto al sistema de su maestro. ¿En qué estaba el fondo de dicho sistema?

Aristóteles lo describe en el Libro I de la Metafísica, cuando dice que Platón descubre la realidad en el mundo de las ideas. Pero el mundo de las ideas - dice Aristóteles- según Platón, está separado de las cosas. Entonces Aristóteles no puede concebir que las ideas estén separadas de las cosas. Y todo el sistema de Aristóteles va a intentar arrancar de aquí: de cómo en las 
cosas está el ser. Entonces, en la dimensión que va del pensamiento al ser, Aristóteles elige otro camino distinto de su maestro. Ya no va directamente a las ideas, sino que va directamente a las cosas. Pero va directamente a las cosas en un aspecto muy determinado. Dice él: "a las cosas que son en cuanto que son". Ese en cuanto que son, diríamos que es el objeto de la Fi-

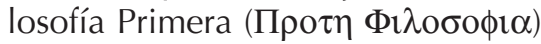
para Aristóteles, el objeto último del pensamiento. O sea que, la interpretación que Aristóteles hace de Parménides es que el pensamiento tiende a las cosas porque en las cosas está el ser, y al estar el ser en las cosas va a considerar las cosas no como cosas, sino en cuanto que son. Ese paso que da Aristóteles, hace que las ideas necesariamente vayan a salir de las cosas, destruye de un plumazo el mundo de las ideas de Platón como separado de las cosas.

A lo largo de la Historia de la Filosofía, en un momento alguien va a preguntarse: ¿Realmente, por qué no nos planteamos si no será el pensamiento mismo considerándose a sí mismo, quien tiene que dar con eso que es ser y no precisamente por la ruta de las cosas?

En el Renacimiento, en los albores del siglo XVI más o menos, - a finales del XV y comienzos del $X \mathrm{VI}$-, el saber de filosofía empieza a volverse hacia el pensamiento. $Y$ comienza a tomarse el pensamiento como objeto, a analizarse el pensamiento, a ver si escudriñando el pensamiento encuentra en su estructura algún tipo de respuesta diferente respecto del ser que descubría en las cosas. Es decir, a ver si encuentra algo en la estructura del pensamiento que de luz sobre el camino (methodos) para llegar al desvelamiento o verdad del ser. Es la tarea intelectual de René Descartes.

$* * *$

Descartes vendría a decirse: "vamos a ver si encontramos un método que nos lleve, con seguridad, del pensamiento al ser". ¿Qué es llevarnos del pensamiento al ser? Es alétheia, es descubrimiento de lo que el ser es. Y entonces Descartes pone sobre la mesa todo lo que es la función del pensamiento visto desde la óptica de la actividad del propio pensamiento.

¿Cuál es el "funcionamiento" del pensamiento visto por Descartes? Pues, el pensamiento lo que hace es ordenar las ideas, analizando y sintetizando (construyendo, podríamos decir). Y ese análisis y esa síntesis de unas ideas respecto de otras es lo que vulgarmente llamamos los juicios.

Emitimos juicios sobre lo que las cosas son. Entonces lo único que va a hacer Descartes es decir: ¿en virtud de qué un juicio es verdadero?, ¿en virtud de qué un juicio 
que yo doy sobre la cosa, descubre lo que la cosa es? ¿Qué aspectos descubre la mente en las cosas que yo pueda decir que eso es la verdad de la cosa en cuanto que ahí está la presencia del ser?

Descartes quiere encontrar algunas ideas, que radicadas en el pensamiento, sean la base que el mismo pensamiento tiene para ir estructurando el conjunto de ideas que por nuestra mente continuamente pululan. Descartes encuentra dos ideas que van a constituir la fundamentación de la verdad de los juicios, es decir, de cómo los juicios que emitimos sobre las cosas llevan en sí — dice Descartes - la claridad y la precisión con las que determinamos lo que las cosas sean. $Y$ a esas dos ideas las va nominar res, las Ilama cosas, son algo ontológico, algo real. Y ¿cuáles son? Esas ideas son para Descartes la idea de extensión y la idea de reflexión; y por otra parte la matemática. La matemática es una ciencia que a la altura del siglo XVI ya está consolidada como una ciencia, es decir, si es verdad aquello que decía Kant que todo saber es saber de objetos, pues la matemática ya tiene su objeto consolidado a la altura cultural del siglo XVI europeo.

Entonces, Descartes ¿qué es lo que ve? Intuye (visión inmediata de algo), que cada vez que yo emito un juicio sobre las cosas sensibles, éstas, las cosas sensibles, se me presentan de muchas maneras. Pero hay una manera que es inmediata al pensamiento. $Y$ esa manera que es inmediata al pensamiento es el hecho de que las cosas son extensas, que se pueden medir. Y como las cosas se pueden medir y son extensas, el aspecto aquel en el que yo emito un juicio apoyándome en la extensión de la cosa, me da la verdad de la cosa. Las cosas son unas respecto de las otras, mayores o menores, se pueden combinar de este modo o del otro; entonces puedo calcular de antemano, por ejemplo, cómo se hace un puente, puedo calcular de antemano cómo se navega en un barco, etc., etc. Empieza a surgir lo que se llama el mundo moderno, apoyados en una idea base, que está presente en todos los juicios que yo emito sobre la realidad que puede ser manipulada por el hombre desde el parámetro que es la extensión.

Leibniz va a añadir sólo un punto de inflexión a esa extensión: La extensión sí, pero también la fuerza. Con la extensión y la fuerza, diríamos, se va a objetivar. Vamos a emitir juicios sobre lo que es la realidad sensible y la realidad cósmica en general. Entonces, esa orientación del pensamiento que va hacia las cosas a través de la extensión y de la energía, diríamos, es la que va a condicionar ya el saber del hombre respecto a las cosas que están fuera, o frente a él.

¿Y respecto a lo que siente dentro de sí, de tal manera que el 
hombre siente que - como dice Descartes- es un ser? Yo soy un ser que piensa, soy un ser que quiere, soy un ser que llora, que ríe, que desea, soy un ser que tal y tal, etc. Pues respecto a todo ese mundo tan rico, tan vivo, interior, ¿en qué idea me voy a apoyar para poder controlar todo esto y poderlo regular, y poder-diríamos- vivir en armonía interior conmigo mismo, y al mismo tiempo en comunicación con los otros que sienten igual que yo? Se encuentra entonces Descartes con otra idea, o res, que la formula como res cogitans.

Cogitans es un verbo latino, cogito significa pensar, la cosa que piensa, que quiere, que siente, etc., etc. O sea, la introspección, que decimos hoy en día, de la persona. Así Descartes lo que hace es desentrañar el pensamiento como tal, pensamiento que va hacia el ser, que tiende al ser.

Descartes deja de lado al ser por un momento como identificado con las cosas y va a entrar en el pensamiento a ver si el pensamiento tiene una estructura tal que apoyándome en esa estructura pueda tener una nueva visión directa del ser. Y ahí da con esas ideas elementales, que son fundamento de todos los otros juicios. ¿Qué categoría ontológica tienen? Es decir, ¿qué realidad poseen? Descartes les da la categoría de res, de cosa. O sea, la cosa aristotélica, el ver las cosas que son en cuanto que son, decía Aristóteles que allí estaba el ser. Pues ahí está el ser. La res extensa no es sólo una idea, sino que es una realidad, una realidad metafísica.

¿Qué significa una realidad metafísica? Que es categorizable metafísicamente ¿Qué significa que es categorizable metafísicamente? Que le puedo poner una etiqueta, una palabra que nosotros estamos empleando siempre y que nos conviene de vez en cuando determinar con precisión, esa es la palabra sustancia.

El término substancia traduce al latín el término griego ovoı $\alpha$. ¿Qué era la ousía para un griego? La ousía para el griego tenía que ver con lo que se llama la "hacienda". Los bienes de los que uno es propietario, de tal manera que esa hacienda proporciona independencia y autonomía para la tarea de irse haciendo la vida. Por lo tanto, ousía era la hacienda, sin ninguna connotación filosófica por supuesto, era una palabra del lenguaje vulgar de la gente. De tal manera que ousía si tiene alguna connotación verbal sería un sustantivo sacado de lo que es el verbo ser en su participio de presente: siendo, lo que es. Lo que es, lo que está siendo.

Pero lo que es, entonces, metafísicamente, desde el punto de vista aristotélico, adquiere toda una profundidad: que lo que es, es $l o$ que está, lo que tiene firmeza, lo que tiene consistencia. Aristóteles 
asumió la palabra, esa vulgar, la ousía, para decir: lo que tiene consistencia desde el punto de vista del pensamiento, es aquello en lo que el pensamiento se apoya para volver inteligible (entender) cualquier cosa que sea, para llegar al ser. La ousía del pensamiento, la hacienda del pensamiento, es precisamente la categoría que indica lo autónomo y permanente.

Y ¿qué es lo autónomo y permanente en el horizonte de la filosofía griega? Pues aquello que a pesar del movimiento, siempre está, o aquello que de alguna manera hace posible que haya movimiento, sin moverse ella (la ousía), a su vez. A esta realidad autónoma permanente e inmóvil, frente a toda realidad que se mueve, Aristóteles la llamó prote-ousía, primera sustancia. Y esa prote-ousía es el Theos, el ser, el dios de Aristóteles. Y como bien dice Xavier Zubiri: es un dios ocioso, no hace nada. Porque él existe akineton, inmóvil, todo lo que hay está en movimiento. Por ello los griegos no concibieron ni la creación, ni la nada...

Pero también Aristóteles habla de deuterai ousíai, las otras, las segundas ousíai, sustancias — vamos a traducir así-. Y esas ousíai ¿qué son? Cualquier cosa que pueda ser objeto de un juicio del pensamiento, de tal manera que se deje nominar, se deje calificar, se deje decir de ella lo que es; pero teniendo en cuenta que la apoyatura del juicio no está en el pensamiento, sino que es el pensamiento el que se apoya en lo que la cosa tiene de ousía. ¿Y qué es lo que la cosa tiene de ousía? Tuvo que nominarlo Aristóteles, y lo calificó de aquello que agarra, de aquello que sostiene lo que es el adorno de la cosa y que nosotros vamos calificando en el juicio que emitimos sobre ella. Y así va determinando con los predicados: la pared es grande, tiene tantos metros, la pared es de color blanco, la casa es confortable, la casa tiene cinco habitaciones, la pared, la casa, etc. Las palabras pared y casa son ahí la ousía. Y todas las otras formulaciones que estamos fijando como predicados, están volviéndose inteligibles por constituir, diríamos, el adorno de la ousía. Así se vuelve inteligible para el pensamiento lo que es esa realidad que llamamos, en el ejemplo, pared o casa. Estamos en un mundo de representaciones: las cosas se nos presentan, el pensamiento las traduce en ideas; y al traducirlas en ideas, las ordena, las une. $Y$ al unirlas, se vuelven inteligibles, ¿por qué? — dice Aristóteles-: Porque todo se vuelve inteligible para el pensamiento que va categorizando (y construyendo, añadimos nosotros hoy).

¿Qué significa categorizar? Hay un verbo en griego que se dice kategoreuo. ¿Y las categorías? ¿Qué es categoría?

Categoría es un asunto intelectual muy importante. Este señor 
tiene mucha categoría, esta dama es de categoría, etc. ¿Qué significa esa importancia que tiene la categoría? ¿Por qué la categoría refleja lo importante?

Kategoreuo significa en griego marcar. El 'agorero' es el que dice cosas importantes en el mundo del destino. Normalmente después, como las cosas importantes suelen ser las que nos perjudican, pues el agorero es aquel que nos dice cosas que no queremos oír. Esto es una desviación del significado. Pero agoreguo, nos lleva a la palabra ágora, la plaza donde se decían las cosas importantes para los griegos. Entonces, agoreuo es el hablar en la plaza, y kata es el prefijo griego que indica el sello, por decirlo así, lo que queda $-k a t a-$, lo que queda bien sellado o fijado. Es la acción de sellar en el sentido de que queda bien sujeta la acción del verbo. Si agoreuo es hablar, katagoreuo es, diríamos, acusar, en el sentido de sellar lo que se está diciendo como una cosa importante. Por lo tanto consistente, inteligible para el entendimiento de las cosas.

Categoría, cuando realmente la mente dice: esto es así, ha categorizado, ha dicho lo que es y lo ha sellado. Entonces esto es una substancia (así tradujeron los latinos la ousía) y esta sustancia está -diríamos- adornada de una serie de simbebekota. Simbebekota es una palabra griega que significa lo que acompaña. Sim-baino, lo que acom- paña a una ousía o sustancia. Los latinos tradujeron por "accidente" (lo que está o sucede junto a -ac-; accidentes, cualidades, atributos etc., etc., etc.) Entonces Aristóteles hace una distribución genial de estos modos de categorizar. Dice Kant, que el libro de las categorías de Aristóteles será perenne. Un libro pequeñito, que probablemente lo escribió a última hora, en sus últimos años para que sus alumnos, los de Aristóteles, pudieran comprender con agilidad toda su obra escrita. Es una auténtica joya.

Descartes, ante ese libro de las categorías de Aristóteles, se pregunta: ¿Cuáles son las categorías sustanciales que tiene el pensamiento para poder decir lo que las cosas son? Pues tiene tres categorías como dijimos arriba, con valor de sustancia. Por tanto son independientes del ejercicio de pensamiento. Necesita el pensamiento apoyarse en esas tres sustancias para poder funcionar en el asunto de la emisión de juicios sobre las cosas. Pero para Descartes funcionar significa ver claro, estar seguro de que hay verdad en lo que se afirma. —Diríamos—, este color rojo ¿es más intenso que este otro color rojo? Respondería Descartes, la intensidad se puede medir, pero lo que no se puede medir es el color rojo como la rojedad, luego ésta, la rojedad como posible sustancia, no tiene valor alguno independientemente de su intensidad que se puede medir. 
¿Qué está indicándonos con ello Descartes? Que ha liquidado de un plumazo inmensos ámbitos posibles para las categorías aristotélicas. Todo lo que Ilaman las cualidades segundas, todo aquello que se percibe por los sentidos y que Aristóteles eleva a categoría de cualidad, esto lo suprime. ¿Por qué? Porque no hay una idea en el pensamiento, salvo la idea de pensamiento mismo — según Descartes—, que avale la seguridad de que estamos verdaderamente categorizando ahí. Sencillamente, estamos opinando sobre colores, estamos en el mundo de la subjetividad, en el mundo de la opinión. El gran marco de Parménides - la tensión entre el pensar y el ser-, condiciona el saber de filosofía de tal manera, que no se puede salir tan fácilmente de sus márgenes.

¿Cuál será la sustancia que Descartes pone como fundamento de todo juicio que se va a dar sobre la realidad? La sustancia clave, la sustancia que nos da confianza y que destierra toda posible duda acerca de la existencia de un engañador más poderoso que nosotros, esa sustancia es Dios. Dios para Descartes es lo más perfecto, y la perfección se confunde con la bondad. Este es el papel, el oficio intelectual de Dios en la filosofía que surge de los análisis cartesianos...

Tenemos pues, que la filosofía moderna se asienta, por decirlo así, dentro del pensamiento. Va a analizar el pensamiento.
Descartes y Leibniz analizan el pensamiento para ver si hay unas ideas en las que yo pueda apoyarme y que constituyan como la sustancialidad, o la categorización de todos los juicios que damos sobre las cosas.

$* * *$

Kant va a dar un paso más sobre este planteamiento. ¿Qué es lo que nosotros captamos - dice Kant-, cuando algo nos afecta? El algo que se nos presenta, dice Kant, nos afecta siempre de una manera muy definida, en un espacio determinado y en un tiempo concreto. De tal manera que cuando yo hablo por ejemplo, de que he conocido a fulano o a mengana, o cuando he dicho que he visto una montaña, un valle, o cuando he dicho que tengo que hacer un viaje, etc., etc. Cuando hablo de toda esas cosas, esas cosas siempre están situadas. Están situadas en un espacio determinado y en un tiempo concreto. Entonces dice Kant, ¿qué es el espacio y el tiempo? ¿Son conceptos? No. Porque el concepto por definición es representación (por construcción decimos nosotros hoy)... Son intuiciones. Son intuiciones, visión inmediata, es una visión inmediata. Es una intuición inmediata. Esa intuición inmediata ¿está fuera de mí? No, porque ya estamos metidos en el pensamiento. Con Descartes ya hemos entrado en el pensamiento y ya no vamos a poder salir. Desde dentro del pensamiento ¿el espacio 
y el tiempo qué son? Son estructuras del pensamiento, en virtud de las cuales el pensamiento (en su dimensión de inmediatez con las cosas, que eso es la sensibilidad para Kant), tiene la capacidad de determinar aquello que le afecta al hombre. Determinarlo, de ponerlo y de dejarlo fijado espacial y temporalmente.

Aprehendemos el pasado, el presente y el futuro. De alguna manera ¿qué vienen a ser?, pues el tiempo. Entonces ¿qué es este tiempo? Para Kant es una forma interior: el modo que tenemos nosotros de localizar las cosas en un antes, en un ahora y en un después. ¿Eso qué es? Eso es un algo inmediato al pensamiento humano, es inmediato. No podemos ni prescindir de ello, ni podemos conceptualizarlo más allá de la inmediatez. ¿Por qué? Porque no podemos separar esa intuición de ninguna cosa que nos afecte. Si hablamos del antes, hablábamos de cosas que nos sucedieron desde este momento hacia atrás, si hablamos del después, hablamos de cosas que queremos que nos sucedan o no, en el futuro. $Y$ isi hablamos del ahora?, pues de cosas con las que estamos en él, en el ahora, en el actual presente, por decirlo así. Por lo tanto, no puede uno separar el tiempo de las cosas sensibles que se nos fijan en la conciencia.

Por otra parte, a su vez, cualquier "cosa" está situada fuera de nosotros en un espacio determina- do. No podemos concebir nada que no esté ahí en un espacio. Esto es lo elemental del conocimiento previo. Es decir, tenemos dos estructuras que pertenecen a la forma del pensamiento, él las Ilama formas a priori, con las cuales nosotros determinamos todo lo sensible. Pero son ciegas — dice—, estas intuiciones o formas a priori de la sensibilidad... ¿Cómo comprendo yo lo que me viene ahí? Lo comprendo porque yo tengo unas categorías que las voy aplicando a las unidades espaciotemporales. A la unidad espaciotemporal, por ejemplo, yo les aplico la idea de hombre, la idea de mujer. $Y$ este es el modo que tiene la mente humana de funcionar.

Kant no inventa nada, reestructura las cosas de otra manera. Si inventa algo Kant, es el modo de analizar esto. $Y$ entonces dice que la lógica, la lógica ésta con la que todos combinamos juicios entre sí, como hemos hecho siempre, tiene una dimensión transcendental.

¿Qué significa transcendental? Significa que esa lógica transciende, está sobre nuestra operatividad, nuestro normal conocimiento de las cosas. Y al transcenderla, se convierte en objeto de nuestro análisis. Entonces podemos analizar cómo funcionan los principios lógicos del entendimiento, cuya función trascendental es avalar nuestros juicios empíricos como juicios diríamos-, que tienen salvedad sustancial ¿De qué?, del buen fun- 
cionamiento trascendental de los principios lógicos.

Ahora bien, dice él, no tengo ninguna experiencia de que estos principios lógicos se puedan aplicar más allá de las unidades espaciotemporales. Por lo tanto, la ciencia como tal es una ciencia de fenómenos, es la ciencia de la organización de los fenómenos. Y ahí empieza la tensión moderna avalada por Kant.

¿Qué significa fenómeno?: La unidad espacio-temporal de aquello que nos afecta. Eso es el fenómeno. $Y$ el fenómeno, entonces, es el contenido de los conceptos que yo, mientras los tengo en mi cabeza sin funcionar, son vacíos. Los conceptos que tenemos, un concepto cualquiera, el concepto de dimensión, el de disponibilidad, el concepto de sustancia, etc., etc., son un bagaje que tengo y lo voy rellenando de unidades fenomenales. Así al combinar yo las unidades fenomenales de más y menos, etc., etc., ya sea cualitativa, cuantitativa, dispositivamente, etc., etc., voy creando formulaciones de tipo universal que van dando de sí los saberes determinados. Formulación de tipo universal sobre el funcionamiento del cosmos, la astrofísica; funcionamiento universal sobre cómo se desarrolla la vida, la biología etc., en el sentido de las plantas, en el sentido animal, en el sentido humano, etc.

Está naciendo un mundo nuevo. ¿En qué? En el hecho de que los filósofos han descubierto que el pensamiento tiene una estructura que está hecha para conocer el ser —que dijo Parménides-, pero el ser ya no es algo que está en las cosas, porque a las cosas a su vez, sólo llego si de alguna manera las determino conforme a la totalización espacio-temporal.

¿Qué hacemos con esa otra parcela de la realidad que, aparte de poderla localizar espaciotemporalmente, tiene como una dimensión que no hemos enunciado aquí, pero que es tan íntima a nosotros o más, que las formas espacio-temporales de determinación? Evidentemente existe la conciencia de que nuestra conducta es una conducta que no está necesariamente espacio-temporalizada, y que no funcionamos - diríamoscomo funcionan los astros por la atracción universal, las fuerzas de la gravedad, etc., etc. Solucionamos los asuntos (o no), porque nos da la gana, porque podemos y porque queremos.

Hay un sentido profundo de la libertad, realmente nos sentimos y somos libres. ¿Qué hacemos con ello? Todo el panorama de la ética, del derecho, de la comunicación humana, del querer o no querer, del odiar y del amor. Dice Kant, ¿qué hacemos con todo ese mundo? El pensamiento encuentra también una estructura dentro de sí para poder regularlo. Y esto es tan importante, tan importante que yo tal vez me 
muera sin saber una cosa: realmente si no hubiera llegado Kant a descubrir esto que vamos a decir ahora, ¿hubiera existido el mundo moderno tal y como lo sentimos y vivimos?

Cómo están complicados los modelos de países que se quieren imitar unos a otros; las categorías de las relaciones comerciales, las categorías de las relaciones diplomáticas, de las relaciones internacionales jurídicas, el respeto a los pactos, etc., etc. Porque Kant viene a decir que en el pensamiento humano hay una estructura a priori, — como hay las formas espacio-temporales y como hay las categorías conceptuales para determinar lo objetivo de la naturaleza, (vamos a decirlo así). Hay también un a priori, un algo a priori que está ahí, desde el cual el pensamiento va universalizando la conducta humana, y la va regulando, y va formulando leyes, que diríamos, hacen posible que los pueblos se aglutinen en federaciones $\mathrm{u}$ otras fórmulas similares. $\mathrm{Y}$ esa realidad interior es algo tan simple e intuitiva como el deber. El deber. Y lo nominó imperativo categórico.

Hay dentro de nosotros una capacidad de legislar, una capacidad de mandar que es absoluta. Lo que pasa es que es subjetiva - dice él-. Es subjetiva, es absoluta, pero también es universal. ¿A qué se debe este universalismo? Porque encuentra dentro de sí como una formulación: procede de tal manera que tu conducta pueda convertirse en conducta universal. He ahí el a priori del deber y consiguientemente, el fundamento de las éticas y en general de eso que podríamos llamar la racionalidad que da vida e identidad a los pueblos.

Kant era de religión cristianaprotestante y además muy practicante, entonces a partir de la filosofía kantiana toda la corriente política protestante se polarizó, como si dijéramos, en estos términos: aquí se fundamenta racionalmente todo un modo de organizar el Estado. Por eso tiene tanta importancia —diríamos-, esa teoría de Kant. Paralelamente a esta situación, discurre Montesquieu sobre la división de poderes, y sobre la fuerza, o el llamado imperio de la ley... Kant converge también en este punto.

Tenemos ya que dentro del pensamiento, descubierta la capacidad para el conocimiento de la naturaleza, y la estructura, a su vez, para la regulación del mundo humano de la libertad y de las apetencias.

La pregunta no se hace esperar para Kant: ¿qué hacemos con aqueIlo que es transcendente? Porque seguimos teniendo la idea de Dios, seguimos teniendo la idea de Hombre libre como inmortal, y seguimos teniendo la idea de Mundo como el cosmos, como algo que da de sí, y que puede seguir indefinidamente funcionando. Este es el objeto últi- 
mo de la metafísica en cuanto que ordenamos los juicios que tenemos sobre esas cosas, hacemos unidades de la totalidad de los juicios. No podemos dar un juicio sobre la realidad de Dios en el sentido de sustancia, de la sustancia antigua, pero sí podemos regular nuestros juicios sobre lo que es lo transcendente. Y entonces regulamos los juicios en unidades de totalidad. Y tenemos dos dimensiones en el pensamiento, dice Kant, con las cuales volvemos comprensible todo el mundo de nuestras apetencias intelectuales, que es el mundo del gusto, - belleza, estética- y el ámbito de lo sublime. Es decir, que Dios para Kant se convierte en lo sublime, porque de alguna manera es lo otro distinto pero que está como realidad amparando todo este orden maravilloso, que va descubriendo con su accionalidad el pensamiento humano.

A Kant no se le ocurrió toda esta concepción en una noche de insomnio, no, sino que Kant arribó seguramente a ello por haber estudiado muy lentamente a Descartes, y a Leibnitz, y a Spinoza. Y a Hume, a Locke y por haber reflexionado sobre la contradicción entre empiristas y racionalistas. Entonces, viene a decir, hay que radicalizar más el análisis del pensamiento. Vamos a analizar las estructuras del pensamiento en función del conocimiento.

En función del conocer, conocer tanto la naturaleza, tópicamente hablando, como conocer nuestro modo del proceder humano, éticamente hablando. Y también por encontrar una respuesta consoladora sobre el hecho de lo que sea la realidad después de la muerte en cuanto que nos afecta, y el hecho del Dios que se nos revela en las religiones. Y qué base racional, a su vez, tiene ese Dios. Esta es la obra de Kant.

Parménides formulaba, como ya sabemos, que el pensamiento tiende al ser, es igual al ser (to gar noein esti to einai): "necesariamente el pensamiento está hecho para el ser", podríamos traducir nosotros. Si así fuere, entonces resulta que el pensamiento se ha confundido en el análisis realizado por Descartes y hasta Kant, —que es toda la filosofía moderna-, y ello por haber identificado la actividad del pensamiento con la figura del conocimiento. Podríamos decir que pensamiento para Descartes, Leibniz, Spinoza, Hobbes, Locke, Hume, Berkeley, etc., Para todos los grandes empiristas y grandes racionalistas europeos del siglo XVII y XVIII, pensamiento es igual a conocimiento. En el sentido que el estudio del conocimiento nos da la mayor virtualidad del pensamiento, lo que el pensamiento puede dar de sí. Y esto todavía hoy funciona así en muchos aspectos... Todavía hoy funciona así, ¿por qué? Porque las grandes ideas avanzan muy lentamente en la historia de la humanidad, vienen siempre por detrás. Yo creo que hay mucho 
kantismo perdido por ahí en el mundo del deber, la ley como deber, el deber, el deber... El deber, eso es kantismo puro. Todavía está influyendo y eso que han pasado doscientos años, y tal vez los que seguirán...

Pero si el pensamiento lo identificamos con el conocimiento resulta que ese conocimiento, ese instrumento del que nos servimos continuamente para decir lo que las cosas son en cuanto que son, en expresión aristotélica, (porque nadie va contra esa fórmula, se situará uno de distinta manera, pero la formulación sigue estando ahí). Entonces, en un momento dado, aparece la figura que realmente domina al conocimiento. ¿Cuál es la figura, la categoría que domina al conocimiento? Pues es la categoría del yo. El yo, el Yo, yo transcendental, el yo que transciende toda operatividad. Es importante esto.

En el momento en que aparece el yo ¿qué es lo que hace el yo? Pensar, ¿qué significa el yo pensando? El yo pone el pensamiento, lo pone, es suyo, lo pone. ¿Quién va a reflexionar entonces sobre la importancia de este yo?... Fichte.

Este yo activo ¿qué es lo que pone el yo?, se pregunta Fichte. Estamos en pleno final del siglo XVIII, principios del XIX. Hay tres grandes filósofos alemanes que son Fichte, Schelling y Hegel: los idealistas alemanes. ¿Qué significa esto? Significa que la idea, desde la idea se constituye la realidad, por decirlo así.

El asunto es: ¿quién posee la idea? Fichte dice que la idea la posee el yo. Por lo tanto, el yo de Fichte es un yo factitivo, un yo que actúa, un yo que hace. (Está empezando a nacer, políticamente por ejemplo, lo que será el imperio alemán).

Hegel declara enfáticamente que va a enseñar a pensar en alemán a toda Europa, y a fe que lo ha conseguido. Este personaje grandioso, el día que Napoleón estaba bombardeando Jena, la ciudad de Jena donde él daba clases, toda su preocupación era salvar un manuscrito, su manuscrito de la Fenomenología del Espíritu. Y se fue corriendo por los arrabales de Jena, pero al mismo tiempo no estaba renegando de Napoleón, porque según Hegel, Napoleón era el ideal o representación histórica del yo que pone (mejor, im-pone) la realidad. Él vio la figura de Napoleón. Intuyó en esa figura de Napoleón, un momento de su elucubración sobre la historia del pensamiento.

Fichte es el primero que dice que el yo pone la realidad, por lo tanto el conocimiento va a ser superado. Por encima del conocimiento está el yo que pone la realidad. ¿Qué es esa realidad para el yo? 
Algo muy elemental y en función del yo. ¿Qué es lo que no es el yo? Pues, es el no yo. No yo. De ahí nace el idealismo alemán. Toda la realidad externa al pensamiento es no yo, y adquiere su inteligibilidad desde el yo que piensa. Pero entonces el yo que piensa ya no sólo es el yo que quiere, etc., etc., etc., sino el yo que impone la realidad. Y pone la realidad, y la impone. ¿Cómo la pone? Pues porque la crea ¿Y cómo la crea? Porque la ordena. ¿Y cómo la ordena? Porque tiene poder para hacerlo. De ahí va a adquirir su racionalidad el pensamiento europeo absolutista...

El yo lo que pone, dice Schelling, es que nos descubre la realidad que está detrás del no yo. Y lo que está "detrás", la realidad detrás del no yo, es la naturaleza. ScheIling fue un idealista, diríamos que fue el padre de todos los grandes ecologistas románticos. La naturaleza es un poco de donde brota todo lo que, de alguna manera, nosotros después vamos transformando racionalmente. Pero la base está en aquello que está representado por el no yo. ¿Por qué?

Porque es un proceso dialéctico. Dialéctico significa que ante la posición del yo, surge el no yo, el no yo deja al descubierto la naturaleza, eso vuelve sobre mí y entonces ya lo que vuelve sobre mí dialécticamente es la configuración, es ya la anexión. Yo me anexiono la naturaleza, y al anexionarme la na- turaleza, ¿en qué me convierto? Me convierto verdaderamente en un ser natural que es más que natural, (esa mezcla en opinión de Hegel respecto de Schelling, era algo así como aquello de "que por la noche todos los gatos son pardos", es decir, que ya no sabemos si somos espíritu, o si somos naturaleza). De ahí que Hegel afirme: hay posición del yo, pero la posición del yo es representación a su vez de la posición del absoluto. Entonces la realidad es lo absoluto como tal, y lo absoluto se va representando como si fuera un film, una película. ¿A través de qué? A través de la conciencia humana. La conciencia humana es el gran film de la realidad. O sea, cuando nosotros vemos una película sobre la realidad, la película no es real, sino que el film nos lleva a nosotros a una realidad determinada pero sólo representada en el tal film de la conciencia. En definitiva, que lo que viene a decir Hegel es que la conciencia humana en su ver todo lo que va pasando por ella ¿qué va descubriendo? Va descubriendo cómo el absoluto se va manifestando a través de dos dimensiones; una que le Ilamamos la historia, la historia de los acontecimientos; y otra, las figuras lógicas de la conciencia.

Ese entrelazado entre el análisis de la historia y las figuras de la conciencia, es la obra de Hegel que se Ilama Fenomenología del Espíritu. El espíritu ¿qué es? El espíritu absoluto. La fenomenología ¿qué es? El modo como aparece el espíritu, 
el espíritu se nos va manifestando en la historia de la humanidad y se nos va aclarando en las figuras de la conciencia.

El despliegue del método. La lógica de Hegel es ir descubriendo la interpretación de este entrelazado, de tal manera que al final sucede lo que estaba en el principio que es lo absoluto en cuanto absoluto. Pero lo absoluto, en cuanto absoluto, la mayor determinación del absoluto, ¿qué es? ¿El ser? No. El ser es lo más indeterminado que hay, afirma Hegel. Por lo tanto Hegel considera no directamente al ser sino su actividad ¿Qué es ese pensamiento en cuanto actividad? Su manifestación más directa la ve Hegel en el mundo griego, en su modo de pensar el ser, y en el mundo escolástico medieval como su primer replanteamiento.

¿Qué hace la Filosofía desde Descartes?, pues tender hacia el pensamiento que se reflexiona a sí mismo, pero se reflexiona a sí mismo como poseedor del conocimiento exclusivamente.

Hegel entiende que el conocimiento es solamente una figura de tantas que tenemos nosotros en la conciencia, y que tendrá que ser interpretada desde otras figuras también: la duda, la certeza, el juicio,... la figura más radical es la razón. Y en cada época histórica hay como una concreción de esas figuras intelectuales. Entonces, el análisis de Hegel consiste en ir viendo cómo se desarrolla la conciencia desde el juego dialéctico entre el pensamiento directo, el pensamiento reflexivo y la independencia entre el pensamiento directo y el reflexivo que es la autoconciencia. Entonces, por ejemplo, tenemos la figura del amo y del esclavo, la época del amo y el esclavo que analiza él en la etapa histórica del emperador romano Marco Aurelio. El esclavo es la conciencia del señor. Sólo que es la conciencia -le Ilama él- infeliz, porque no goza del poder que tiene sobre el señor. Pero el señor a su vez no puede hacer nada sin el esclavo, entonces necesariamente surgirá la emancipación como síntesis en la que se resuelve la tal contradicción.

En la figuras lógicas, en la impresión sensible, la certeza sensible. Ese "es" del juicio, "esto es un libro", ¿qué fuerza tiene? Ninguna, porque esa fuerza del es, toda la fuerza del es, es el esto. ¿Y el esto qué es? Lo más indeterminado que hay, luego estamos apoyando la certeza de un juicio en algo muy indeterminado; y en un ser que de alguna manera no tiene ningún tipo de entidad precisamente porque expresa lo más indeterminado, la nada. Entonces ¿dónde nos encontramos? Estamos tocando la nada, dice Hegel. Pero no podemos permanecer en la nada. Salimos despedidos desde la nada hacia el ser. Ese revolver de la nada al ser es el devenir. 
Esta figura del devenir que ahí está, es la que va alumbrando las distintas figuras de la conciencia hasta llegar a la última figura de la conciencia que es la razón, la razón en cuanto universal, pasando por la razón subjetiva (el gran descubrimiento de Descartes), pasando por la razón objetiva de Kant, hasta llegar a la razón universal o espíritu, que es Hegel, Hegel mismo.

Hegel ve que toda la realidad no es nada más que representación de la evolución del espíritu. El espíritu, al final, ¿cómo se manifiesta? Cuando ha llegado hasta el final esta dialéctica de la lógica, entonces se manifiesta en un tercer libro que Hegel titula La enciclopedia de las ciencias. Ahí se manifiestan los distintos saberes que han ido surgiendo a lo largo de toda la historia de la humanidad. Pero esos distintos saberes tienen una dimensión subjetiva (siempre la dialéctica de lo subjetivo, lo objetivo y lo absoluto). No está bien decir que un momento dialéctico niega al otro. En realidad el uno asume al otro, la palabra alemana es aufgebung. Aufgebung significa absorber. Asumir lo que hay, transformándolo en un momento superior. Entonces, lo subjetivo queda absorbido en lo objetivo, y lo objetivo queda absorbido en lo absoluto.

Según Hegel, el espíritu subjetivo cuya manifestación fundamental hace posible el ámbito de los saberes, lo constituyen las ciencias subjetivas. Las ciencias que se refieren al sujeto humano, las ciencias anímicas como la sicología, etc., se quedan a veces reasumidas en ciencias objetivas. De las objetivas como la física, las matemáticas, etc., quedan reabsorbidas a su vez, en las ciencias absolutas como es para Hegel la filosofía y la teología.

Como existía el mundo estético de Kant, así se dan también las ciencias subjetivas del mundo estético. La religión es la ciencia subjetiva por excelencia para Hegel pero como ciencia de la religión. Las religiones son un conocimiento de lo transcendente que los pueblos tienen dentro de lo subjetivo. ¿Dónde queda asumida esa subjetivización? en lo objetivo dentro del mundo estético: Todas las manifestaciones artísticas.

Para Hegel, ¿cuál es lo absoluto que absorbe esta realidad?, ¿qué saber es ese? La filosofía-teología. Toda la filosofía de Hegel es una teología porque todo acaba en lo absoluto. Y en lo absoluto, ¿cuál es la representación absoluta de lo absoluto? Pues sería Dios. ¿Cuál es lo absoluto en cuanto absoluto?, dice Hegel, el concepto. Y el concepto es libertad. En último término el sistema de Hegel desemboca en la libertad. Todo esto es grandioso. $¡ Y$ todo ello sin salirse del puro pensamiento!

Hay una cita de Zubiri a propósito de esta grandiosidad de Hegel. 
Está tomada de su libro, Problemas fundamentales de la metafísica occidental (Alianza Editorial, Madrid, 1994, p. 289): "Este hombre debió de vivir en un perpetuo festín porque en cada momento debía de tener la íntima, la irrefragable fruición de inteligir y seguramente la tuvo; que se equivocase es otra cuestión".

Hegel es como la culminación de todo lo que hemos descrito en la relación del pensamiento y el ser. Hegel acaba su Enciclopedia de las ciencias con aquel famoso aforismo de la Metafísica de Aristóteles, en que la realidad última es el pensamiento que se piensa así mismo: noésis noeseos, dice Aristóteles. En último término ese era el Theos para los griegos. Así acaba Hegel la Enciclopedia de las ciencias, citando cuatro líneas en griego, como diciendo: "aquí completo yo lo que Aristóteles y Platón dijeron". Para Hegel ahí remató la filosofía.

Podríamos decir que estamos en la cordillera del Everest, en la cima de la Filosofía. Entonces la Filosofía en un momento dado queda totalmente agarrada, sellada, categorizada en la determinación máxima del concepto. Y la máxima determinación del concepto ¿qué es? Libertad. ¿Por qué? Porque todo este proceso, lo único que está demostrando es la libertad del absoluto que ha llegado a ser eso...

Nuestra individualidad ¿qué es? Para los que son antihegelianos, no es nada, somos inexistentes. Kierkegaard ante este panorama entiende que la filosofía no está hecha para que el hombre pierda toda su esperanza metido en el ámbito de las ideas. Sino que hay que dar un vuelco e ir a lo más real y más inmediato para el hombre. Lo más inmediato para el hombre no son las ideas que tiene en el pensamiento, sino su propia existencia, entender su propia existencia. Comprender la propia existencia, de esta comprensión nacerán las nuevas ideas. Esta es la postura de Kierkegaard frente a las filosofías idealistas.

Otra postura, la de Nietzsche respecto a Hegel y todo lo que comportaba este idealismo. Eso es lo que yo Ilamaría "la voracidad del logos". O sea que, Nietzsche entiende que el logos es algo voraz. ¿Cómo devora? Devora la realidad convirtiéndola en una lógica determinada. Por eso odiaba tanto a Platón y en su tanto al cristianismo metamorfoseado por las ideas platónicas. Porque es la voracidad del logos. ¿Qué es lo que hay que hacer, según Nietzsche? Destruir todo eso. ¿Y desde dónde hay que destruirlo? Colocándonos en la postura más irracional, entendiendo por postura irracional lo más lejano y contradictorio al logos platónico-hegeliano.

Nace así la corriente Ilamada tópicamente de los autores de la sospecha. Sospecha de las posibilidades radicales de la razón. La razón no es tan poderosa como 
han creído todos los que desde Parménides hasta este momento histórico se apoyaron en la fuerza del pensamiento, (aunque los clásicos griegos creyesen en la fuerza del pensamiento porque el pensamiento se encontraba enfocado al ser). Y siempre que daba con el ser se fortalecía el pensamiento. Si se alejaba del ser el pensamiento se desvanecía. Los modernos, como hemos visto, dejaron al ser de lado como término orientador y entraron de Ileno en el pensamiento. Al entrar de lleno en el pensamiento, todavía Descartes conserva las categorías clásicas, pero Kant toma la figura del conocimiento, la desentraña, y los idealistas acaban ya por afirmar que nuestro pensamiento activado no es más que el reflejo de la representación del absoluto, del espíritu que se manifiesta desplegándose, etc., etc.

Entonces vienen los autores de la sospecha y dicen: la razón humana que hace todo ese proceso no es tan potente. Por lo tanto, la lógica con que se actúa ahí, no es una lógica que por definición esté identificada con la realidad en la medida que funcione bien, sino que no tiene que ver nada con la realidad porque la razón está condicionada. Ya la razón aquí empieza a depender de la conciencia. Esa razón o conciencia está condicionada por algo previo a la conciencia y a la razón.
Marx viene a decir que la conciencia se forma no en una razón que vuelve sobre sí misma, sino que se determina para el hombre según su situación, según su posición. Seguimos (im)poniendo... siglo XIX, según su posición en las relaciones de las fuerzas de producción. Aquí habría que remitirse al ensayo de lgnacio Ellacuría: Filosofía de la realidad histórica. Todo lo que es la idea de Hegel para nosotros hasta aquí, y su contraste con el materialismo dialectico y el materialismo histórico, está perfectamente descrito en ese libro. (Filosofía de la Realidad Histórica, está editado en la UCA, de San Salvador y en la editorial Trotta de Madrid).

Freud, ¿Qué viene a decir Freud? Viene a decir que el hombre cuanto más se deja llevar de la razón, más demuestra su enfermedad... significa que está controlada por los deseos de los que no es consciente en su operatividad racional. A través del estudio de la esquizofrenia llegamos a comprender cómo se va formando la conciencia humana desde el deseo interior del thanatos, de la autodestrucción.

La Filosofía va a intentar acotar mejor su campo de reflexión. Entonces se empiezan a negar realidades no porque no existan o dejen de existir, sino porque no son las realidades que pueda afrontar la Filosofía. De alguna manera la Filosofía se propone alcanzar algo de realidad sólo con la fuerza de 
lo que produce la mente. ¿Qué es lo que produce la mente con más fuerza, con más coherencia, con más posibilidades de conseguir evidencias, aunque haya que reducir inmensamente el campo de operatividad mental? Surgen entonces las filosofías del lenguaje: filosofías lógicas, filosofías analíticas. Tal vez el autor más significativo de estas filosofías, por decirlo así, haya sido Witgenstein.

En el lenguaje encontramos aquello a lo que realmente podemos acceder. Si no podemos decir algo de una cosa, lo mejor es callar. Si yo no puedo hablar de Dios porque Dios no entra en el lenguaje directamente, sino analógicamente por medio de metáforas, etc., pues no hablemos filosóficamente de Dios.

En esta amalgama de diversas corrientes de pensamiento en el ámbito de los positivismos, pragmatismos e historicismos de comienzos del siglo XX, empieza a vivir filosóficamente nuestro autor, Xavier Zubiri.

$* * *$

Zubiri se forma académicamente, fundamentalmente, en la dirección de Ortega y Gasset. Ortega ya ha acabado su carrera de filosofía y llega a Alemania alrededor de los años 1906 a 1908. Zubiri está por entonces en la escuela, en San Sebastián, tenía siete años solamente.
Ortega llega y ante este panorama, lo primero que hace es estudiar lo que él entiende que es lo último de la filosofía. Y lo que él cree que es lo último de la filosofía son estas interpretaciones de Hegel y las interpretaciones de Kant. Porque para Ortega, Marx no es un metafísico puro, por lo tanto deja todas esas corrientes a la sociología, él no las estudia. Desde el punto de vista de la metafísica, Ortega, de entrada, va a por la interpretación de Kant. Descubre que Kant, como él afirma en un ensayo en el centenario de la muerte de Kant, quien entra en el kantismo queda encerrado en la interpretación que tiene del conocimiento. No salimos nunca de Kant. Damos vueltas siempre a lo mismo: Que el pensamiento, si se pone a reflexionar sobre sí mismo para encontrar el ser, esa reflexión sobre sí mismo consiste radicalmente en estudiar la estructura del conocimiento, pero de ahí nunca se sale. Entonces con esa especie de briIlantez intelectual que tiene Ortega, se presenta en España anunciando: "Señores, les vengo a prevenir a ustedes, porque yo he conseguido salir de Kant, si nadie sale de Kant, yo he conseguido salir de Kant".

Con el tiempo se dirá que tampoco consiguió salir... Dejémoslo ahí, el hecho es que, como suele decirse, "dio la voz de alarma".

Explica a Kant en unos cursos maravillosos hasta los años 20 en que describe el modo único cómo 
se puede salir de Kant. Dice: los alemanes tienen una vía para salir de Kant, que es la fenomenología. ¿Cuál es el origen de la fenomenología? El origen de la fenomenología está puesto a la par, en el origen de lo que se llama la ciencia de la psicología que empieza a aflorar entonces, a finales del siglo XIX.

Hay un filósofo alemán, Von Bretano, (gran estudioso de los griegos como todos los filósofos que se precien de tal). Cuando Hegel era estudiante y no tenía en la cabeza todo lo que es la idea última como comprensión del todo, se fijó en un autor griego que es Heráclito. Cuando Heráclito dice: $\pi \alpha \nu \tau \alpha$ $\rho \varepsilon 1$, panta rei, "todo fluye", "no nos podemos bañar dos veces en el mismo río". Heráclito por haber dicho eso no ha pasado a la historia de la filosofía. ¿Qué quiso, entonces, decir Heráclito? Quiso decir Heráclito que en la dimensión del pensar al ser, el ser se descubre en el hecho de que el todo está en movimiento. El ser no es algo fijado a la manera de Parménides, pero el ser es. Lo que sucede es que la ruta del pensamiento al ser, es una ruta envolvente, es una ida que siempre está circulando, es el pensamiento el que tiene que enrolarse para llegar al ser. Eso es lo que le impactó a Hegel.

¿Qué le impactó a Marx de su lectura de los presocráticos, en concreto, de Demócrito? Pues que la realidad última no está depen- diendo de algo que es como una fuerza extraña y ajena a esa misma realidad. Entonces la realidad es dialéctica en el sentido de que se va desarrollando, desplegando, pero es una dialéctica que nace del hecho de que todo es material, (por contraposición al principio de reflexión), todo es materia y en un momento dado la materia se vuelve reflexiva. En ese momento en que la materia se vuelve reflexiva, estamos ante la historia.

Pero volvamos a recuperar a Von Brentano, este autor estudia a Aristóteles. Hay una corriente a finales del siglo XIX, que es una nueva lectura de Aristóteles a propósito de la obra de Werner Jaeger. Entonces hay una nueva lectura de Aristóteles. ¿Qué significa esto? Que nos fijamos en el Aristóteles que reflexiona sobre lo que es lo inmediato, el pensamiento. $Y$ así se reactualiza todo lo que es la Metafísica de Aristóteles, el tratado De anima y el Libro de las categorías. Aquello que tiene que ver con el análisis del pensamiento.

Hace su aparición la fenomenología, que consiste en analizar la estructura del pensamiento desde el primer momento en que el pensamiento se pone a funcionar. Zubiri, en su libro Naturaleza, Historia, Dios, tiene un estudio titulado "Hegel y el problema metafísico". Hace unas agudísimas puntualizaciones a Hegel y al inicio de la fenomenología. Es una conferencia que dicta el 
año de 1931 en Madrid, nada más volver de Alemania. Ortega en esa conferencia vino a decirle: "Vd. por el modo radical que tiene de plantear los problemas, pasará muchas dificultades para que le entiendan su metafísica, pero es que nunca he oído una mejor exposición de Hegel que la que $\mathrm{Vd}$. acaba de hacer".

Con la fenomenología seguimos en el esquema del "pensamiento que tiende al ser", pero ya nos estamos cuestionando qué es el pensamiento, por qué el pensamiento cuando piensa, piensa algo de-necesariamente. ¿Esa necesidad, qué está indicando? Que el pensamiento no es lo radical y primario, sino que lo radical y primario es aquello que activa el pensamiento.

Pero si resulta que el pensamiento, según Parménides, está hecho para el ser, hay que volver a criticar el ser, hay que volver a analizar ese ser, no vaya a suceder que ese ser haya tenido tales reducciones a lo largo de toda la historia del pensamiento, que el ser de Parménides y este ser que ahora nosotros comentamos, o estamos comentando, no se parezcan en absoluto.

Se va cambiando, por decirlo así, la fisonomía del ser, el ser como sustancia (identificada o no con su esencia), el ser, pura materia, el ser, el puro espíritu, el ser etc., las cosas en cuanto que son, -por ejemplo-, entes. El ser y el ente se funden para los escolásticos. Es el modo radical de interpretación del medio aevo. Se hacía necesario revisar todo este planteamiento.

¿Quién viene a revisarlo? El ser como tal ser, lo revisa Heidegger, es la filosofía de Heidegger, iya!, pero apoyándose en el pensamiento. $\mathrm{Y}$ partiendo del pensamiento canaliza la fenomenología. Por lo tanto, tendremos que ver cómo la fenomenología canaliza el pensamiento. ¿Y por qué lo tenemos que ver? Porque Ortega es el primero que introduce la fenomenología en la filosofía española, y lo que es más importante en la lengua castellana. El primero, el primero,...

Hay un espléndido libro de un colombiano, Danilo Cruz. Un libro estupendo. Este hombre encontró unos inéditos de Husserl. Estamos hablando de los años 50, ahí en Alemania, los encontró y los tradujo y escribió un libro que tituló una Filosofía sin supuestos. Es un espléndido libro. Husserl cree que él encuentra una filosofía sin supuestos, entonces Heidegger dice: sí, pero hay todavía un supuesto. Husserl (su maestro por cierto), se mueve en el mundo de los entes y no en el mundo del ser. Luego, Vd. tiene el supuesto todavía de los entes sobre el ser. Heidegger entiende que la posición radical es descubrir el ser por otra vía distinta de la de los entes. Y eso se descubre desde la existencia humana (Dasein), porque el pensamiento humano está 
hecho para desvelar el ser, no para desvelar las cosas en cuanto que son, sino el ser directamente. Se inicia así una nueva búsqueda del ser. Zubiri entiende que por ahí no hay salida. Heidegger hace del tiempo, digamos, que un mito para expresar el ser.

Ser y tiempo es la obra de Heidegger. Hay que irse a otra vía, una que esté más allá del ser. ¿Qué vía está más allá del ser? Zubiri la va a llamar la vía de la realidad. Hay que describir esa realidad.

Ortega, en la lección XII de su librito Unas lecciones de metafísica, dice: "Partimos a la conquista de una seguridad radical que necesitamos porque, precisamente, lo que por lo pronto somos, aquello que nos es dado al sernos dada la vida, es radical inseguridad. Necesitamos hacer pie, hallar algo firme entre lo que hay y nos preguntamos qué es lo que verdaderamente hay, cuál es la realidad."

El estudio de la filosofía de Xavier Zubiri es el estudio de esta realidad. Zubiri va a repensar todos estos planteamientos desde la ribera que le sitúa más allá del ser como comprendido por una conciencia. Previa a esta comprensión del ser está la aprehensión en la impresión sensible, de la formalidad de realidad de la que el ser sólo es su actualización en el mundo.

Esta es la tarea de todo estudioso de la filosofía y muy en concreto de los planteamientos de los que ha de partir una investigación de corte doctoral. 